\title{
IDENTIFICATION OF BEHAVIORAL RISK FACTORS DURING PREGNANCY
}

\author{
Florina RUŢA \\ florina.ruta@umftgm.ro \\ Monica TARCEA \\ monica.tarcea@umftgm.ro \\ Victoria STERE \\ victoria.stere@yahoo.com \\ Zoltan ABRAM \\ abram.zoltan@umftgm.ro \\ Călin AVRAM \\ avram.calin@umftgm.ro
}

UNIVERSITY OF MEDICINE AND PHARMACY TÎRGU MUREŞ, ROMANIA

\begin{abstract}
Exposure to smoking during pregnancy is known to be one of the main modifiable risk factors, which threatens maternal and child health. Along with this factor, are not to be neglected also other risk factors belonging to lifestyle sphere, such as alcohol, sedentary, irregular daily meal serving plan, lack of knowledge.

Main objective is identification of behavioral risk factors during pregnancy in a group of recently given birth women, hospitalized in three maternities of Tirgu Mures County.
\end{abstract}

\section{Keywords}

Pregnancy, smoking, lifestyle, intervention

\section{Introduction}

Smoking and its negative consequences represents a real public health problem in Romania. Data from World Health Association (WHO) for Romania show that smoking was responsible for $16 \%$ of noncommunicable diseases also $20 \%$ of all transmissible diseases [1]. The proportion of deaths attributable to smoking was approximately $24 \%$ for men and $6 \%$ for women. From the total premature deaths, nearly one in four (for those aged between 30-44 years) also one in three (for those 
aged between 45-59 years) were attributed to tobacco use $[2,3]$.

According to the Global Adult Tobacco Survey - GATS 2011 conducted by the Ministry of Health, Romania suffered huge damage due to tobacco, by the fact that smoking kills 33,000 people annually, $70 \%$ of these aged between 35-69 years. One in four deaths occurs before age 35 years and is caused by diseases related to smoking. On average, in Romania, smokers prematurely deceased had lived 21 years longer without this vice. The costs entrained with this situation involves the loss of about 26611000 euros, which corresponds to $11.2 \%$ of GDP. In conclusion, in addition to the consequences of exposure to smoking are being felt at the level of various functions of society, they also contribute to increased costs due to premature deaths. Thus, to reduce the number of diseases caused by smoking also implicitly the costs entailed by these diseases, requires a reduction in smoking prevalence. Increasing the rate smoking cessation is considered the only high-impact strategy that can lead to short-term improvement [3, 4].

Alcohol consumption in pregnancy, besides the fact that threatens maternal health, affects the embryo growth and development [5], with possible damage on organogenesis. Brain and central nervous system damage, the occurrence of congenital malformations in the fetus, can also be consequences of exposure to the toxic action of alcohol during intrauterine life. Healthy development of the child after birth, may be threatened by low birth weight, lower IQ, growth and development retard, with influences on emotional behavior in childhood and after this period [6].

The role of exercise in combating smoking in pregnancy was revealed by studies that showed in the case of pregnant smokers, practitioners of physical exercise, a reduction in craving to smoke. Therefore, exercise may have the potential to help, especially in the initial stages of attempting to smoking cessation during pregnancy [7].

Caffeine consumption is part of the daily life of most individuals, but in pregnant women case was assessed as a risk factor, to a daily intake of $300 \mathrm{mg}$ caffeine.

Knowing the exposure level to behavioral risk factors, during pregnancy can be the starting point in application of a sanogenous management for pregnant. Ensuring success in the fight to protect mother and child health lies not only to health care providers but also to family and society.

\section{Methods}

We conducted a cross-sectional study, held from October to December 2014.

Data collection was conducted on a sample of 481 recently given birth mothers admitted in three maternity hospitals in Târgu Mureş County, which completed a questionnaire about behavioral risk factors of lifestyle during pregnancy. Respondents were informed about the study purpose and also on assurance of personal data confidentiality.

Data statistical analysis obtained from the questionnaires was done after centralization of data in an Access database and statistical analysis was performed using the IBM SPSS Statistics Base Authorised User V 22.

\section{Results}

In the studied group, from a total of 481 women, more than half came from urban areas $(58.84 \%)$ while a rate of $41.16 \%$ was represented by women from rural areas of Mureş County. The mean age was 29.5 years.

\subsection{Lifestyle behavioral risk factors}

Smoking: In the first phase of the study we watched the women's behavior towards smoking and we found that a number of 144 $(29.81 \%)$ declared themselves either former smokers or active smokers in the moment of questioning, while a percentage of 338 declared that they never smoked.

Further we focused on identifying other behavioral risk factors among smokers compared with the presence of the same factors among women who declared that they never smoked.

Alcohol consumption: $3.05 \%$ of smokers have consumed alcohol weekly, while only 
$1.40 \%$ from non-smoking group declared weekly alcohol consumption (Figure no.1).

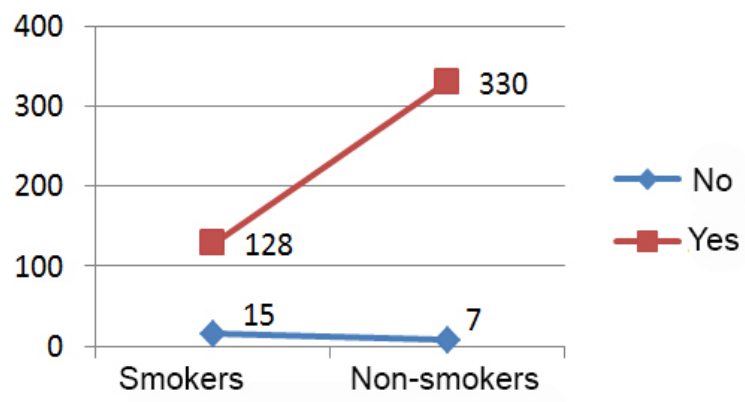

Figure no. 1 Alcohol consumption among pregnant women compared to smoking

Physical activity: More than half of female smokers $(19.01 \%)$ and of those who said they never smoked $(41.78 \%)$ did not do physical activity at all or regularly sports activities, during pregnancy.

A difference can be observed for casual sports activities, $6.33 \%$ of smokers women have done casual sport while a higher value $21.36 \%$, was found in women non-smokers.

Coffee consumption in an amount of among smokers $(67.18 \%)$ than non-smokers women $(42.95 \%)$. A minimum consumption of three cups of coffee daily, was highlighted in a proportion of $3.63 \%$ only among smokers women (Figure no. 2).

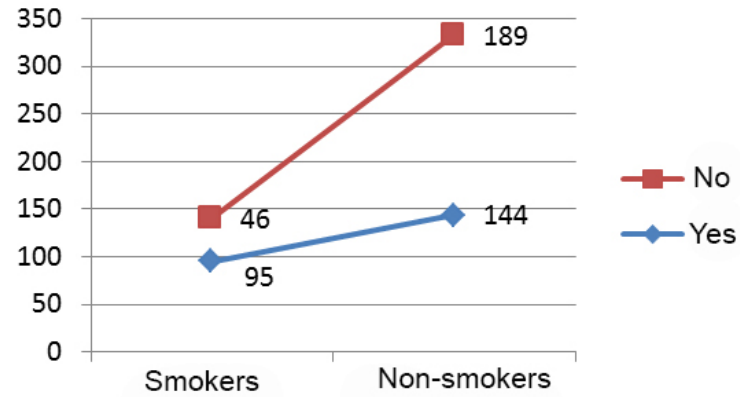

Figure no. 2 Coffee consumption among pregnant women

Attitude towards food: On this topic we identified that a share of $2.81 \%$ from smokers women group have not had a regular daily schedule of dining, while among non-smokers women the percentage for a chaotic food timetable was smaller, $1.72 \%$ respectively (Figure no. 3 ). 1.2 cups per day was more frequently

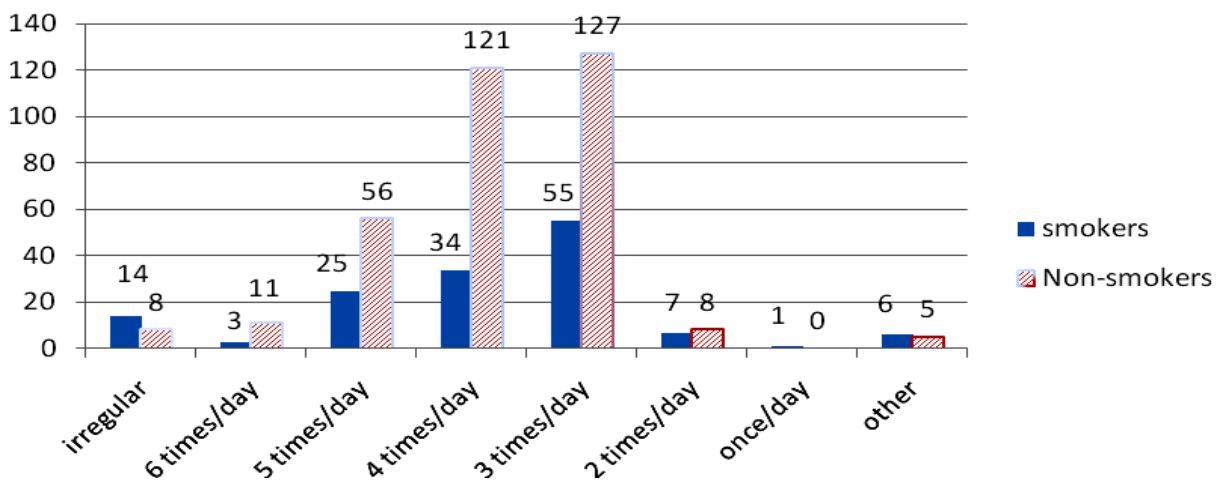

Figure no. 3 Meal schedule among smokers and former smokers

Following the answer to the question "to what extent were you concerned about nutrition during pregnancy" $14.78 \%$ of smokers women during pregnancy have declared little or not concerned at all and in the nonsmokers group, the percentage of those with little or not preoccupied at all about nutrition was only $23.62 \%$ (Figure no. 4 ).

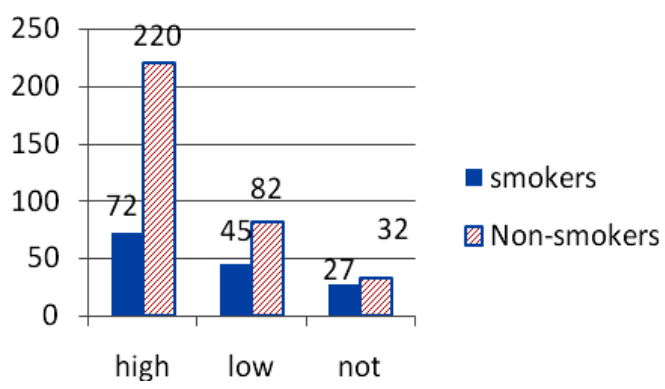

Figure no. 4 Smorkers preoccupation about pregnancy nutrition compared with non-smokers 


\section{Discussions}

Appropriate managing of behavioral risk factors and lifestyle, requires first for the risk groups the access to information, preventively through health education. At the population level, optimizing interventional methods to combat modifiable risk factors that may threaten the health of fertile age women, it must be prioritized.

Healthy lifestyle of young women will not only ensure the health of the mother but also will create a favorable environment for a possible future pregnancy. A protective environment for the pregnancy evolution in order to reduce the fetus exposure risk as much as possible, will ensure its optimal development. Exposure to smoking, increased consumption of caffeine and alcohol during pregnancy, was commonly described as potentially threatening the woman and child health $[8,9,10]$.

At the general population level, it was estimated that by removing, at any age, the one and most important behavioral risk factor, smoking, decreasing the risk of morbidity and mortality would be significant $[11,12]$. Also, the variability of socio-economic, socio-cultural, and psychosocial factors may constitute the context in which the attitude towards smoking manifests differently from one group of subjects to another [13].

Smoking during pregnancy has been considered a major public health problem [14] globally, but with high potential of prevention. The variability of influence factors, mentioned above, probably explains the differences between smoking prevalence values from one region to another. Therefore, smoking during pregnancy is decreasing in high-income countries, while it is strongly associated with poverty in middle-income countries $[14,15]$.

In regional studies conducted in Romania, the prevalence of smoking in pregnancy have identified a value of $24 \%$ of pregnant smokers in a study conducted on a sample of 160 pregnant women hospitalized in three maternity hospitals in Bucharest [16], while another study in Brasov, this time on a large sample of subjects $(n=23.139)$ estimated the same amount of $24 \%$, the rate of smoking in pregnancy [17].

Meghea and collaborators, started in 2008 in two clinics from Cluj-Napoca County, a study that included only female subjects, aged over 18 years, admitted in Obstetrics and Gynecology sections. As a result of data collected has been identified $26 \%$ women consumers of tobacco before pregnancy period but which have renounced as soon as they found that they are pregnant, while about $15 \%$ continued to smoke during pregnancy [18].

Similar studies conducted in close-time periods in other countries with similar geocultural characteristics such as Poland and Hungary, highlights similar data to those obtained at regional level in Romania.

In Poland, the study on a sample of 136 pregnant women identified a rate of smoking among these of $25-30 \%$, which has increased to $33-41 \%$ that after measuring the level of cotinine in study participants saliva [19].

Within the project "Increasing Capacity for Tobacco Research in Hungary", conducted between years 2008-2013, the proportion of women who kept smoking habit, and also after they found that are pregnant, was $26,13 \%$ [20].

Pregnancy is a good opportunity for smoking cessation, clearly evidenced by the high percentage of abandonment by women in the moment they found that will become mothers, quantified at the value of $20-45 \%$ [21].

The value of results obtained by us on a sample of 481 subjects is closest to values coming from a neighboring region, following the study conducted by Meghea et al, respectively the prevalence of smoking during pregnancy by a value of $12.88 \%$ [18].

Existence of data from regional studies conducted only in Romania, may be the explanation for the difference between the values obtained by us compared to those published in other European countries, considering our group as being unrepresentative at national level because we included only the young mothers admitted in 
the three main maternity hospitals from Mureş area.

Higher frequency of alcohol consumption, we highlighted in our study as being more increased among smokers whether this consumption was declared for the the period prior pregnancy or even referred to the period of pregnancy.

Although there are recommendations for physical activity in pregnacy, from the Department of Health and Human Services (DHHS) of the United States [22], which indicates at least 150 minutes per week of moderate physical activity, aerobic type, in our area identified tendency was that of reduced physical activity both by pregnant smokers and those non-smoking. Recommendations regarding the duration and intensity of these activities, adjusted for pregnancy evolution, are assigned to health professionals, so as not to constitute a threat to the mother and child [22].

Regarding coffee consumption, previous studies have described the daily intake of more than $300 \mathrm{mg}$ of caffeine, as being directly associated with miscarriage and low birth weight $[23,24]$. Our study revealed a daily excess amount of coffee recommended for consumption in pregnancy only among pregnant smokers.

Along with lifestyle factors described above, joins eating behavior that may become a risk factor for the pregnant woman health, if does not ensure optimal nutritional requirements both in terms of quantity, quality and respect of a daily serving meals program.

Healthy behavior through diet and respecting a daily serving meals program should be implemented at the general population level and addressed primarily to women, whether it is the pregnancy period, preparation for pregnancy or not [25].

Following the results obtained by our study, the necessity of an integrated approach of behavioral risk factors in pregnancy becomes relevant and it is preferably instead of isolated measures against one or other of the risk factors analyzed in this study.

Expanding studies designed to determine the prevalence of risk behaviors, nationally, primarily adressed to the female population of childbearing age, should identify the need to improve optimal health services for prevention and intervention methodology from suppliers of these services, healthcare professionals with the aim of influencing the sanogene election by targeted population.

\section{Conclusions}

Motherhood as a special period in the life of every woman, was identified as an optimal opportunity to abandon the exposure risk factors threatening the health of mother and child, the most obvious being tobacco use by high dropout rate associated with this period. Therefore, by intensifying information campaigns of young women who are preparing for a future pregnancy or not, we can expect an increase in healthy behaviors in prenatal period and also a postnatal maintaining of these healthy habits.

Its a real challenge for the General practitioners, Midwifes or Nutritionists Dietitians, for the individual, the family and the society also to find the bestways of community intervention in order to reduce risks factors of lifestyle, avoid complications and to maintain the health of the mother and fetus.

\section{Aknowledgement}

This paper is supported by the Sectoral Operational Programme Human Resources Development (SOP HRD), financed from the European Social Fund and by the Romanian Government under the contract number POSDRU/159/1.5/S/133377/ 


\section{References}

1. F. Athabe, A. Aleman, A. Mazzoni et. Al., "Tabacco cessation intervention for pregnant women in Argentina and Uruaguay: study protocol", Reproductive Health no.10, (2013):44.

2. K. Bergman, P. Sarkar, T.G. O'Connor, N. Modi, V. Glover, "Maternal stress during pregnancy predicts cognitive ability and fearfulness in infancy", Biol. Psychiatry, 67(11), (2012): 1026-1032.

3. I. Berlin, G. Grange, N. Jacob, M.L. Tanguy, Nicotine patches in pregnant smokers randomized placebo controlled, multicenter trial of efficacy, BMJ, 348, (2014): 1622

4. K. Bjarveit, A. Tverdal, Health consequences of sustained smoking cessation, Tob Control, no.118, (2009):197-205

5. T. Borlan, A. Babauan, S. Irfan, "Exploring the adequacy of smoking cessation support for pregnant and postpartum women", BMC Public Health, no.13, (2013):472.

6. L.W. Chen, Y. Wu, N. Neelakantan et. al. "Maternal caffeine intake during pregnancy is associated with risk of low birth weight: a systematic review and dose response metaanalysis", BMC Med, 12(1), (2014): 174.

7. R. Doll, R. Petro, J. Boreham, I. Sutherland, "Mortality in relation to smoking: 50 years'observation on male British doctors", Br Med J,328, (2004): 1519.

8. R.L. Duffy, American Dietetic Association Complete Food and Nutrition Guide; (USA: John Wiley \& Sons Publishing House, 2012).

9. A. Fogarasi-Grenczer, Increasing capacity for tobacco research in Hungary 2008-2013, (Budapest: Institute for the History of Hungarian Sciences, 2013).

10. Z.S. Lassi, A.M. Imam, S.V. Dean, Z. Bhutta, "Preconception care: caffeine, smoking, alcohol, drugs and other environmental chemical/radiation exposure", Reprod Health, 11(3), (2014): S6.

11. C. Meghea, D. Rus et. al., "Smoking during pregnancy and associated risk factors in a sample of Romanian women, European Journal of Public Health, (2010, 22 2): 229-253.

12. M. Moga, Gh. Preda, "Smoking in pregnancy", JEPE, 9, (2008): 566-73.

13. I. Munteanu, M. Trenchea, C. Puscoiu, F. Mihaltan, "Smoking prevalence of pregnant women in Romania: smoking effects on new borns", CHESTI, (2007): 132-256.

14. G. Negişanu, Tratat de Nutriţie, (Brumar Publishing House, 2005).

15. S. Nguyen, I. von Kohorn, "The importance of social networks on smoking: perspectives of womenwhoquitsmokingduringpregnancy", Matern Child Health J, 16 (2012): 1312-1318

16. R. Peto, A.D. Lopez, J. Boreham, M. Thun, Mortality from smoking in developed countries 1950-2010, 2nd edition, (Imperial Cancer Research Fund, Oxford, UK World Health Oxford University Press).

17. K. Polanska, W. Hanke, W. Sobala, J. Jurewicz, "Exposure to tobacco smoke of pregnant women-results of prospective study in Lodz region", Przegl Lek, 64, (2007): 824-6.

18. H. Prapavessis, S. De Jesus, T. Harper, A. Cramp, M.F. Fitzgeorge, M. Ussher, G. Faulkner, P. Selby, "The effects of acute exercise on tobacco cravings and withdrawal symptoms in temporary abstinent pregnant smokers", Addict Behav., 39(3), (2014):703.

19. J.S. Tolstrup, S.K. Kjaer, C. Munk, L.B. Madsen, B. Ottesen, T. Bergholt, M. Gronbaek, "Does caffeine and alcohol intake before pregnancy predict the occurrence of spontaneous abortion?", Human Reproduction 18(12), (2003): 2704.

20. V.T. Tong, J.R. Jones, P.M. Dietz et. al. Trends in Smoking Before, During and After Pregnancy - Pregnancy Risks Assessment Monitoring System (PRAMS), (United States, 31 sites, 2000-2005, MMVR 58(4): 1-29). 
21. U.S. Department of Health and Human Services. ODPHP Publication, (UOO36. Washington, DC, USA: U.S. Department of Health and Human Services; 2008. 2008 Physical Activity Guidelines for Americans.http://www.health.gov/PAGuidelines/).

22. World Health Organization - WHO Global Report: Mortality attributable to tobacco, (World Health Organization, Geneva, Switzerland, 2012).

23. World Health Organization. Tabacco Factsheet, (World Health Organization, 2011).

24. World Health Organization: World Health Report 2002, (Geneva: World Health Organization, 2002).

25. Zhu ZH, Lee M, Zhuang YL, Gamst A, Wolfson T., "Interventions to increase smoking cessation at the population level: how to much progress has been made in the last two decades?"; Tobacco Control, vol. 21, no. 2, (2012): 110-118. 